\title{
Is the Capacity for Optic Nerve Regeneration Related to Continued Retinal Ganglion Cell Production in the Frog? A Test of the Hypothesis that Neurogenesis and Axon
Regeneration are Obligatorily Linked
}

\author{
J. S. H. Taylor ${ }^{1,2}$, J. L. Jack ${ }^{1}$, and S. S. Easter, Jr., ${ }^{1,3}$ \\ 'The MRC Neural Development and Regeneration Group, Department of Zoology, University of Edinburgh, Edinburgh EH9 3JT, \\ UK \\ ${ }^{2}$ Department of Human Anatomy, University of Oxford, Oxford OX $13 Q X, U K$ \\ ${ }^{3}$ Department of Biology, University of Michigan, Ann Arbor, MI-48109, USA
}

Key words: retinotectal, Xenopus, development, optic nerve, regeneration

\begin{abstract}
In the central nervous system of fish and frogs, some, but not all, axons can regenerate. Retinal ganglion cells are among those that can. The retinae of fish and frogs produce new retinal neurons, including ganglion cells, for months or years after hatching. We have evaluated the hypothesis that retinal axonal regeneration is obligatorily linked to continued production of new ganglion cells.

We used bromodeoxyuridine immunocytochemistry to assess retinal neurogenesis in juvenile, yearling, and 10 year old Xenopus laevis. Retinal ganglion cell genesis was vigorous in the marginal retina of the juveniles, but in the yearlings and the 10 year olds, no new ganglion cells were produced there. Cellular proliferation in the central retina was evident at all three ages, but none of the cells produced centrally were in the ganglion cell layer.

Regeneration was examined in vivo by cutting one optic nerve and then, weeks later, injecting the eye with tritiated proline. Autoradiographs of brain sections showed that the optic nerves of all three ages regenerated. Regeneration in vitro was assessed using retinal explants from frogs of all three ages. In all cases, the cultures produced neurites, with some age-specific differences in the patterns of outgrowth.

We conclude that retinal axonal regeneration is not linked obligatorily to maintained neurogenesis.
\end{abstract}

\section{Introduction}

Axons in the optic nerve of fish and amphibians can regenerate and re-establish appropriate connections following axotomy (Matthey, 1927; Gaze, 1959; Attardi and Sperry, 1963). Although one is tempted to generalize from these results that all central axons in anamniotes can regenerate, this has recently been shown not to be true. When the spinal cord in goldfish was cut, some tracts regenerated, but others did not (Bunt and Fill-Moebs, 1984). Axons from nucleus isthmi in Xenopus did not regenerate (McCart and Straznicky, 1988). Lyon and Stelzner (1987), working on adult frogs, made single diencephalic lesions that severed axons of both retinal and tectal neurons, and then showed that the retinal axons regenerated across the lesion, but tectal axons did not. Several control experiments convincingly excluded less interesting interpretations and the authors concluded that the two populations of neurons must be intrinsically different in some respect(s) that enabled the axons that originated in the retina, but not those from the tectum, to elongate. The authors pointed out one difference-that the retina was still producing new neurons, including ganglion cells, while the tectum was not. The cessation of tectal cell proliferation during the early period of post-metamorphic life has been described (Straznicky and Gaze, 1971; Reh and Constantine-Paton, 1983; Grant and Keating, 1986; Kollros, 1988; Kollros and Thiesse, 1988). Lyon and Stelzner implied that continued cell proliferation might be accompanied by other events that are essential for the outgrowth of new axons, and that these events might enable severed axons from retinal ganglion cells to 


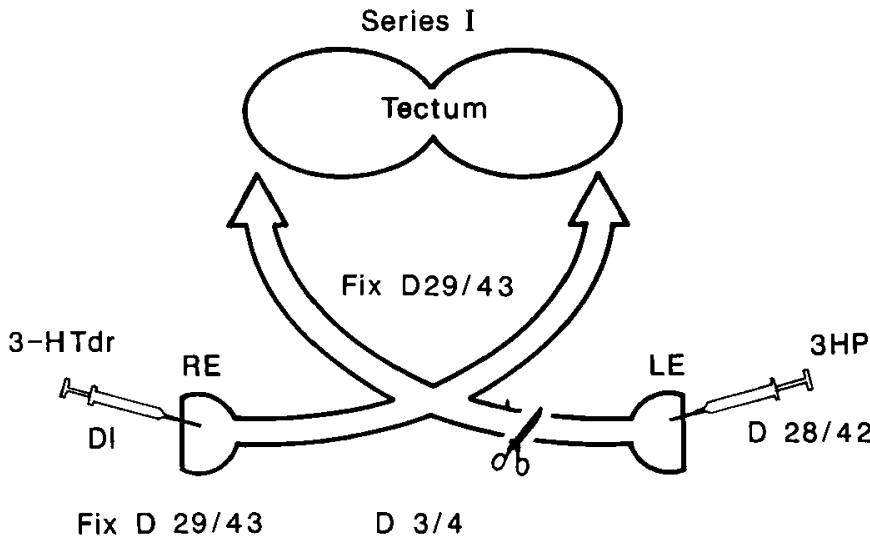

Fix D $29 / 43$
D $3 / 4$

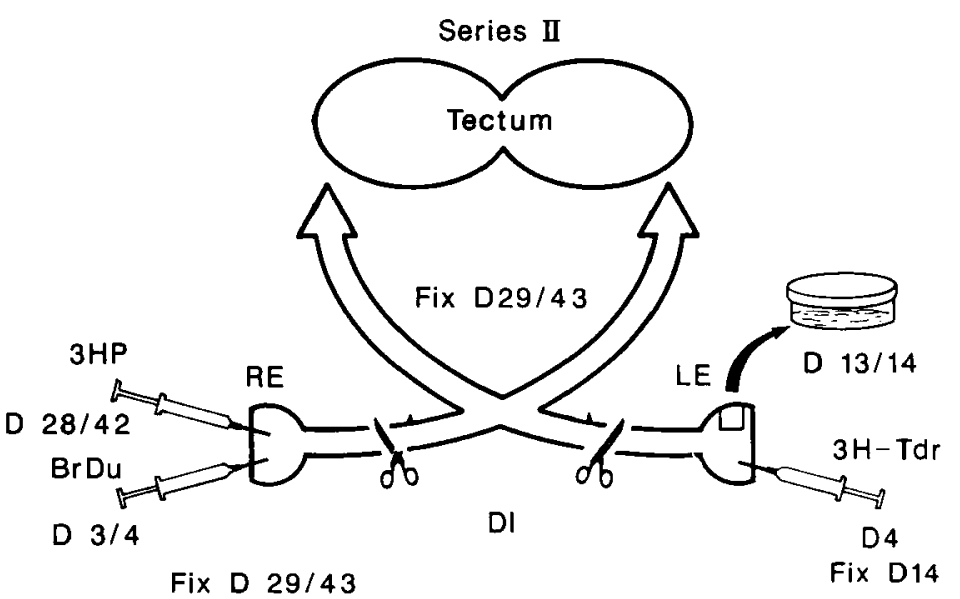

FIG. 1. Outline of the experiments. In these diagrams, the right and left eyes (RE and LE) are shown, connected by two curving arrows to the optic tectal lobes (Tectum). The scissors indicate nerve section, the syringes indicate intraocular injection, and the abbreviations give the compounds injected (3HTdR: tritiated thymidine; 3HP: tritiated proline; BrdU: bromodeoxyuridine). The letter D, followed by a number, indicates the day on which a procedure was carried out. See Materials and methods for details.

regenerate, but not tectal axons. The possible link between continued neurogenesis and regenerative success was developed further by Holder and Clarke (1988).

Both the nature and the existence of these special events that enable central axonal regeneration are speculative. They might be either intrinsic or extrinsic to the ganglion cells. For example, the proliferating retinal cells might release growth factors that other retinal cells need for outgrowth. A growth factor might induce the ganglion cells to synthesize growth associated proteins, thought to be essential for axonal elongation (Skene and Willard, 1981; Kalil and Skene, 1986; Moya et al., 1988). Alternatively, one could imagine that the new axons continuously joining the optic nerve of a growing retina might provide something, or stimulate glial cells to provide something, such as a substrate molecule, required for optic axonal elongation (Hopkins et al., 1985). Should proliferation cease, then the synthesis of growth factors (first example) or the provision of substrate molecules (second) would cease, and severed axons, by hypothesis, would be unable to elongate. These particular examples are offered only to make the hypothesis concrete; we do not plan to test either of these specifically. Instead, we ask a more general question: is central axonal regeneration possible in a system in which neurogenesis has ceased?

The preliminary answer, drawn from the optic nerve literature, is, 'no'; retinal ganglion cells in fish and frogs regenerate well and their retinae proliferate, while ganglion cells of birds and mammals do not (Goldberg and Frank, 1980; Richardson et al., 1982), and their retinae have ceased proliferation. But this is an unsatisfactory comparison, since anamniotes and amniotes differ in many fundamental respects, and the difference in regenerative ability might equally well be attributed to any of them. What is needed is a comparison between more closely related species or, better still, between different stages of the same species.

Xenopus laevis appears to fit the description, as Grant and Keating (1986) have recently reported that the retinae of adult Xenopus (defined as 2 or more years past metamorphosis) did not label with tritiated thymidine, and therefore did not proliferate. If this were true, then the experiment could be done: adult Xenopus would have their optic nerves crushed, and if neurogenesis were essential to regeneration, then the nerves would not regenerate.
This is the prediction that we have tested. But before doing so, we thought that we should check the conclusion of Grant and Keating (1986) because of a potential problem in their approach. They injected tritiated thymidine systemically into their 10 year old frogs, but in an amount $(25 \mu \mathrm{Ci})$ that would translate into only about $0.5 \mu \mathrm{Ci} / \mathrm{gm}$ body weight. This is well below the more commonly used $10 \mu \mathrm{Ci} / \mathrm{gm}$ body weight-so low, in fact, that one can doubt whether dividing cells would be adequately labelled for autoradiography. Accordingly, we used tritiated thymidine and bromodeoxyuridine, injected intraocularly, to assess retinal proliferation.

\section{Materials and Methods}

Frogs of three ages were used in these studies: recently metamorphosed (juvenile), 1 year old (yearling), and 10 year old (adult) Xenopus. They were either reared in our own laboratory or purchased from Xenopus Ltd (Redhill, Surrey). In each age group two parallel series of procedures were performed to investigate retinal proliferation and axonal regeneration (see Fig. 1). They will be described briefly here, and more extensive details, where appropriate, will be given below.

Series $I$. The right eye was injected with tritiated thymidine on day 1. Three or 4 days later, the left optic nerve was cut. After 4 weeks (juveniles and yearlings) or 6 weeks (adults) the left eye was injected with tritiated proline, and after one more day, the animal was killed. The brain and the right eye were processed for autoradiography. The thymidine labelled nuclei in the eye should reveal the progeny of those cells that had been dividing at the time of the thymidine injection, and thus give a measure of the proliferative activity in the retina. Labelled neuropil in the retinal projection sites in the brain was interpreted as evidence for regeneration of tritiated proline labelled optic axons.

Series II. Both optic nerves were cut on day 1. Three or 4 days later the right eye was injected with bromodeoxyuridine (BrdU) (Gratzner, 1982), and the left eye with tritiated thymidine. Ten or 11 days later, the left eye was removed and a portion of its retina was explanted for tissue culture, to assess optic axon outgrowth in vitro. The remainder of the left eye was processed for autoradiography to reveal thymidine 

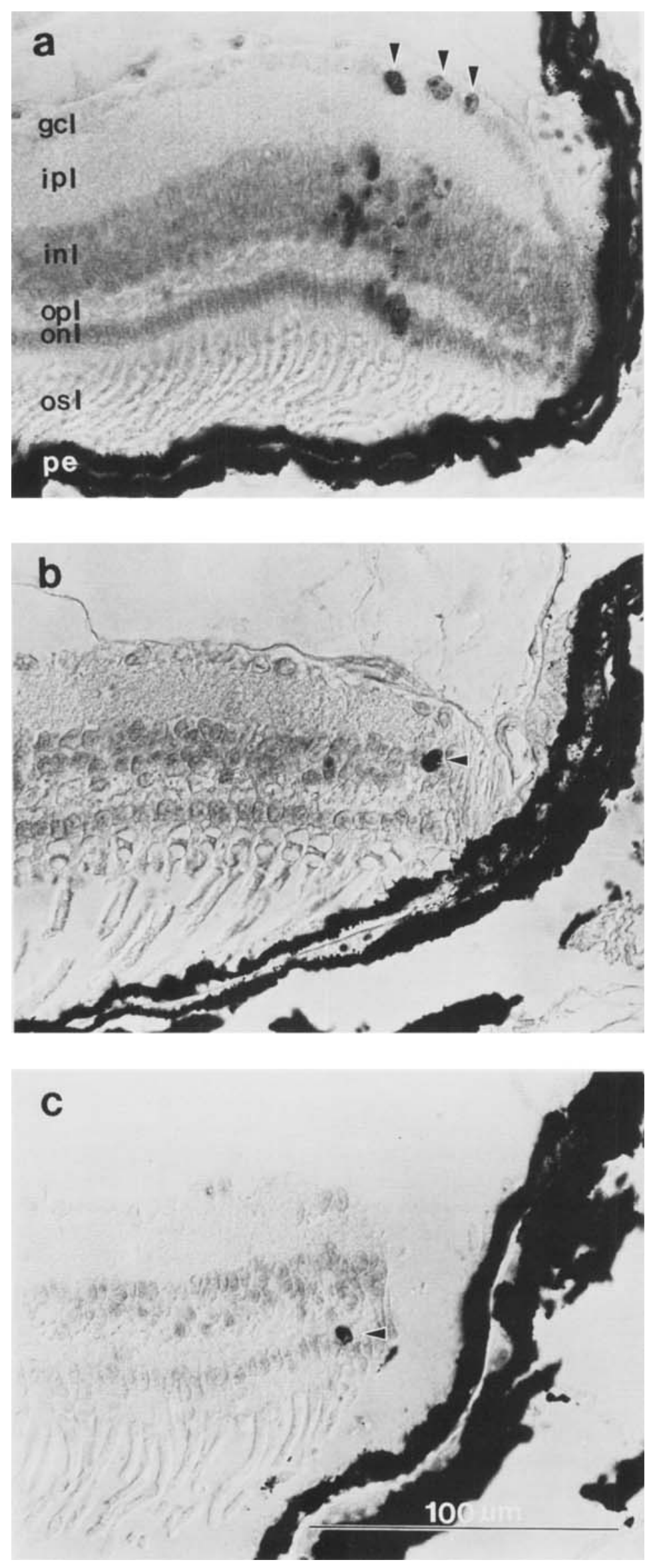
labelled nuclei, and thus the existence of cell proliferation soon after the lesion. After a further delay of 4 weeks (juveniles and yearlings) or 6 weeks (adults) the right eye was injected with tritiated proline, and after 1 more day, the animal was killed. The right eye was processed for anti-BrdU immunocytochemistry to reveal the progeny of those cells that had been proliferating 4-6 weeks earlier. Note that the BrdU had been given several days after sectioning the nerve, and therefore should reveal any proliferation that might have been stimulated by the surgery. The brain was processed for autoradiograpy to reveal regenerated optic axons labelled with tritiated proline.

We had originally hoped to trace regenerates using anterograde transport of horseradish peroxidase (HRP), which works well in younger Xenopus (Taylor and Gaze, 1985). We found that the adult frogs did not transport HRP, whether assessed in whole mounts of the brain or in sections, and therefore, we used tritiated proline.

All procedures were carried out on animals deeply anaesthetized by immersion in MS222 (ethyl-m-amino benzoate, Sandoz) at the following concentrations ( $\mathrm{gm} / \mathrm{ml}$ water): juveniles 1:4500, yearlings 1:3000, and adults $1: 1000$. The animals were marked on the back with identifying numbers by cautery, allowed to recover in oxygenated diluted saline, and returned to their home aquaria.

Optic nerves were sectioned intracranially. The animal was positioned on its back, and the lower jaw held open to expose the roof of the mouth. The oral mucosa was cut and the cranium penetrated at the level of the chiasma using a dental drill. The nerve(s) was (were) repeatedly teased and/or crushed with fine forceps or sharpened tungsten needles, until visible separation of the tissue was evident. The mucosal lining of the roof of the mouth was sutured to close the wound.

All injections were made directly into the vitreous. Tritiated thymidine and BrdU were given in amounts dependent on the weight of the eye which was estimated from its diameter, assuming a specific gravity of unity. The dose of tritiated thymidine (TRK $686,1 \mathrm{mCi} / \mathrm{ml}$, Amersham) was $10 \mu \mathrm{Ci} / \mathrm{gm}$ of eye weight, and that of $\mathrm{BrdU}$ (Sigma), $0.5 \mathrm{mg} / \mathrm{gm}$ eye weight. Tritiated proline (TRK $5341 \mathrm{mCi} / \mathrm{ml}$, Amersham) was given at a dose of $5 \mu \mathrm{Ci}$ for juveniles and yearlings and $20 \mu \mathrm{Ci}$ for adults.

Retinal fragments were cultured as follows. After washing the eye in three changes of sterile Niu-Twitty saline containing $5000 \mathrm{IU}$ gentamicin, the sclera was ruptured and a piece of retina was removed from the peripheral part of the temporal quadrant. The pigment epithelium was stripped away and the explant washed in Niu-Twitty, and then placed in culture medium. Our culture medium was a dilute L-15 (60\%; Gibco) solution containing 10\% fetal calf serum (Sera Lab), and the following additives: putrescine $1.6 \mathrm{mg} / \mathrm{ml}$; insulin, $0.5 \mathrm{mg} / \mathrm{ml}$; glucose, $6 \mathrm{mg} / \mathrm{ml}$; transferrin, $0.5 \mathrm{mg} / \mathrm{ml}$; and glutamine, $0.3 \mathrm{mg} / \mathrm{ml}$ (all obtained from Sigma). Explants were grown on acid-cleaned glass coverslips, silanized and coated in laminin $(40 \mu \mathrm{g} / \mathrm{ml}$, Gibco $)$. To improve initial adhesion of the explants to the substrate, a thin piece of sterile polyacrylamide gel was placed on top of the explant and held in place with a fragment of glass slide. The gel was removed after $16 \mathrm{~h}$ and the cultures were grown in a moist atmosphere at $23^{\circ} \mathrm{C}$.

Histological methods were as follows. Brains and eyes destined for autoradiography were fixed for $24 \mathrm{~h}$ in a mixture of acetic acid, formalin, and ethyl alcohol (AFA), then dehydrated, embedded in wax, and cut as serial $10 \mu \mathrm{m}$ sections. The brains were cut transversely, the eyes, radially, without specific orientation. Approximately 20 sections through the centre of the eye and all sections through the diencephalon and midbrain were dipped in Ilford $\mathrm{K} 2$ emulsion, exposed in the dark for 14 days, and developed in Kodak D-19 to reveal silver grains. They were counterstained with cresyl violet.

The BrdU-injected eyes were fixed for $2 \mathrm{~h}$ in $2 \%$ tricarboxylic acid (TCA), soaked in $70 \%$ alcohol overnight, dehydrated, and embedded in wax. Radial $10 \mu \mathrm{m}$ sections were cut (without specified orientation), and mounted on glass microslides. Typically about 50 sections through the centre of the eye were dewaxed, incubated in $2 \mathrm{~N} \mathrm{HCl}$ with $0.3 \%$ Triton X for $30 \mathrm{~min}$, washed in phosphate-buffered saline (PBS), and placed in a $10 \%$ sheep serum in PBS. After washing in PBS, mouse anti-BrdU (Becton Dickenson) was placed on the sections and left for $30 \mathrm{~min}$ at $4^{\circ} \mathrm{C}$ in a moist chamber. The sections were again washed, then incubated for $1 \mathrm{~h}$ in HRP-conjugated rabbit anti-sheep serum. After further washing, the sections were reacted for HRP histochemistry using diaminobenzidine (DAB) as chromogen. They were counterstained with neutral green.

Sections were photographed on a compound microscope (Leitz Orthomat) equipped with differential interference optics.

\section{Results}

\section{Control experiments}

Four control animals, 2 yearlings and 2 adults, were prepared from series II to test the effectiveness of our optic nerve lesions. Two days after bilateral optic nerve section both eyes were injected with tritiated proline and the animals were killed after $24 \mathrm{~h}$. All retinae were fixed, sectioned, and processed for autoradiography along with the brains. In all 8 cases the retinae were heavily labelled, therefore the injections were successful. Of the 8 visual pathways (left and right sides in the 4 brains), 7 were unlabelled, and 1 was partially labelled, including the tectum. We conclude that the intracranial lesions were generally successful.

\section{Cell proliferation}

The results of each of the age groups will be presented in turn.

Juveniles. (i) BrdU. All the results were from retinae that survived 4 weeks after injection. Of the original 10 juveniles, 2 died before the BrdU analysis, and 2 more were spoiled in the histological processing. The surviving 6 produced similar results, consistent with previous descriptions drawn from tissue labelled with tritiated thymidine (Hollyfield, 1971; Straznicky and Gaze, 1971; Jacobson, 1976; Beach and Jacobson, 1979; Straznicky and Hiscock, 1984; Hoskins and Grobstein, 1985; Grant and Keating, 1986). Near both retinal margins, a band of labelled nuclei, usually with representatives in all three nuclear layers, was evident (Fig. 2a). These are the descendants of the proliferative marginal cells that picked up the BrdU at the time of injection. Peripheral to the band of labelled cells was a band of unlabelled ones, the descendants either of BrdU labelled precursors whose label was diluted below the level of detectability, or of unlabelled precursors. The length of the retina peripheral to the labelled band indicates the extent of retinal growth since the BrdU was injected.

In addition to the peripheral bands, isolated labelled cells and nests

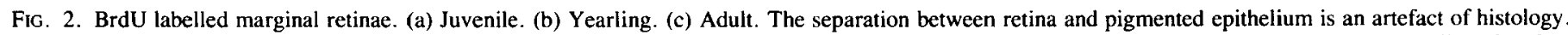

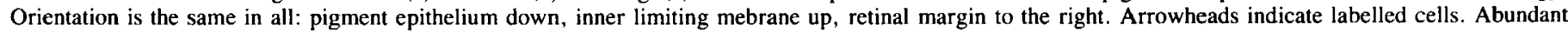

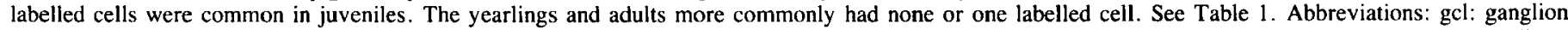

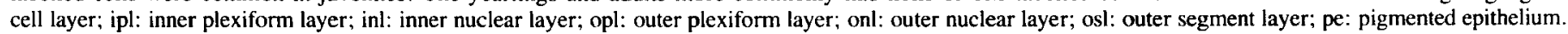



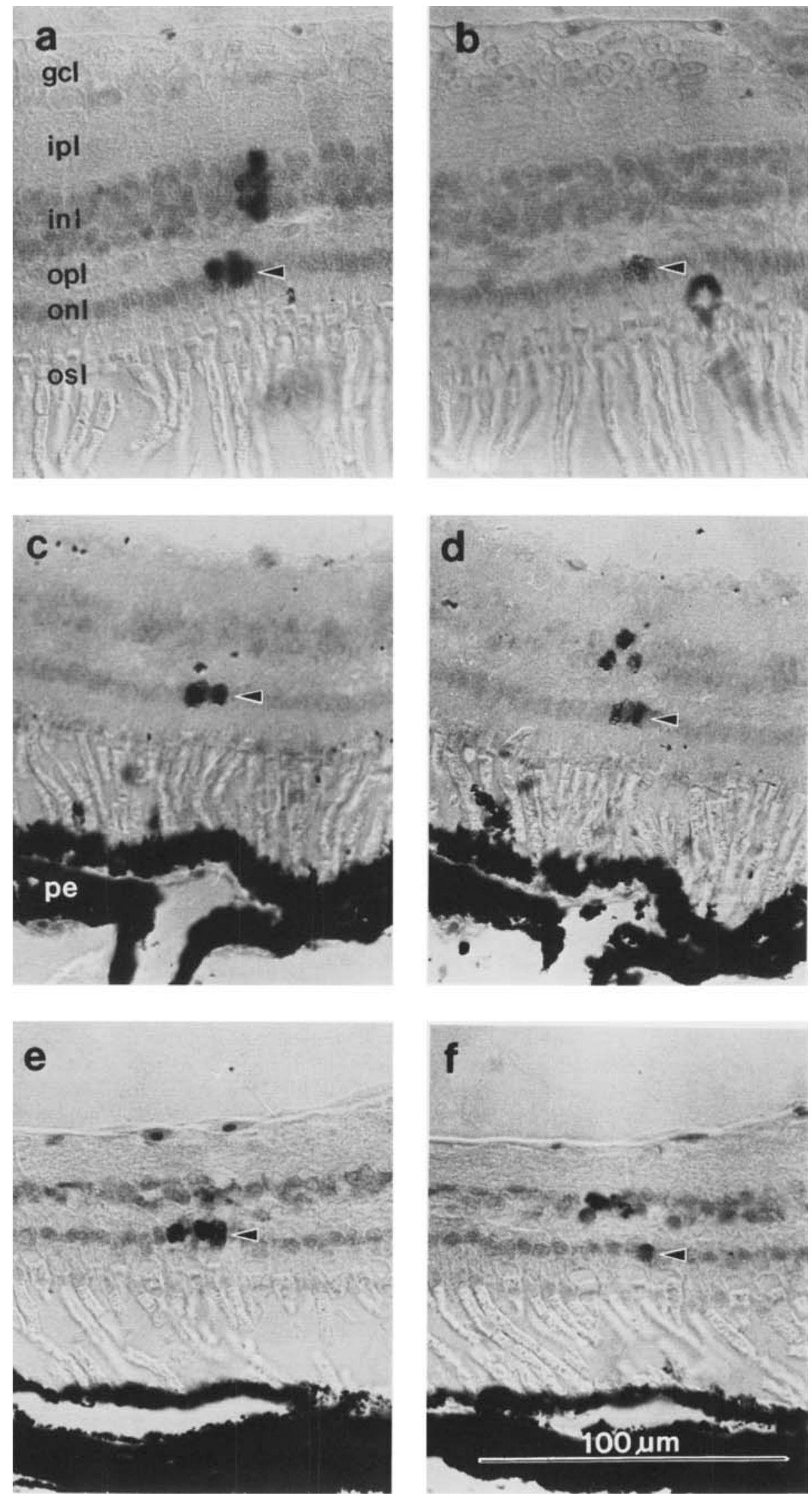
TABLE. 1. Quantitative aspects of cell proliferation as assayed by $\mathrm{BrdU}$ labelling.

\begin{tabular}{|c|c|c|c|c|c|c|c|c|}
\hline \multicolumn{9}{|c|}{ Juveniles } \\
\hline ID & 591 & 592 & 593 & 595 & 597 & 598 & Mean & SD \\
\hline MR & 1.0 & 1.0 & 0.83 & 1.0 & 1.0 & 1.0 & 0.97 & 0.07 \\
\hline CR & 10 & 9 & 7 & 28 & 6 & 7 & 11.2 & 8.38 \\
\hline \multicolumn{9}{|c|}{ Yearlings } \\
\hline ID & 611 & 612 & 615 & 616 & 618 & & Mean & SD \\
\hline MR & 0.05 & 0.35 & 0 & 0 & 0.17 & & 0.11 & 0.15 \\
\hline CR & 3 & 11 & 0 & 0 & 10 & & 4.8 & 5.36 \\
\hline \multicolumn{9}{|c|}{ Adults } \\
\hline ID & 629 & 631 & 632 & 633 & 635 & 636 & Mean & SD \\
\hline MR & 0.08 & 0.10 & 0.05 & 0.08 & 0 & 0 & 0.05 & 0.04 \\
\hline $\mathrm{CR}$ & 7 & 3 & 3 & 2 & 9 & 1 & 4.17 & 3.13 \\
\hline
\end{tabular}

ID: identifying number for each animal.

MR: the fraction of marginal retinae that were labelled. The first 20 sections (40 margins) were examined for each animal.

CR: the number of clusters of labelled cells in the first 20 sections. When successive sections had labelled cells in the same region, a single cluster was scored.

Mean and SD: summary statistics for each row.

of labelled cells were scattered in central retina (Fig. 3a,b). The nests frequently extended across $2-3$ sections with $1-4$ labelled cells per nest. The labelled nuclei were in either the inner or the outer nuclear layers, or in the inner plexiform layer, but they were never found in the ganglion cell layer. Similar nests have been reported in the Xenopus retina (Hollyfield, 1971; Grant and Keating, 1986). They resemble the rod precursors of teleost fish (Johns and Fernald, 1981; Johns, 1982).

This description suggests, by its similarity to earlier autoradiographic studies following injection of tritiated thymidine, that the BrdU did not interfere critically with normal retinal growth and that incorporation of BrdU was not toxic, at least for the dose and survival times used here. The BrdU results are summarized in Table 1.

(ii) Tritiated thymidine. Nine of the frogs in series I, and 8 of those in series II survived to produce autoradiograms of the eyes. The labelled cells were found primarily near the retinal margin and, less frequently, in central retinal nests. But in nearly all of the retinae, there were very few labelled cells by comparison with previous studies (cited above) and with the BrdU results of this study. We believe the low yield of labelled cells is attributable to radiation-induced cell death caused by the tritiated thymidine. Our reasons for this belief are given in the Discussion; in the remainder of the Results, we will emphasize the BrdU findings.

Yearlings. (i) BrdU. All of the results were from animals that survived 4 weeks after injection. Of the original 10,2 were used as controls (see above), leaving 8 for BrdU labelling. Of these, 3 retinae were very sparsely labelled, and 5 completely unlabelled. The total absence of label could have resulted from a genuine absence of cellular proliferation in the retina or from some technical problem, such as a failed injection of the BrdU or mistakes made in the immunocytochemical staining. Two of the unlabelled retinae were accompanied in the same sections by large numbers of labelled cells in the cornea (Fig. 4), so the immunocytochemistry was apparently not faulty. We

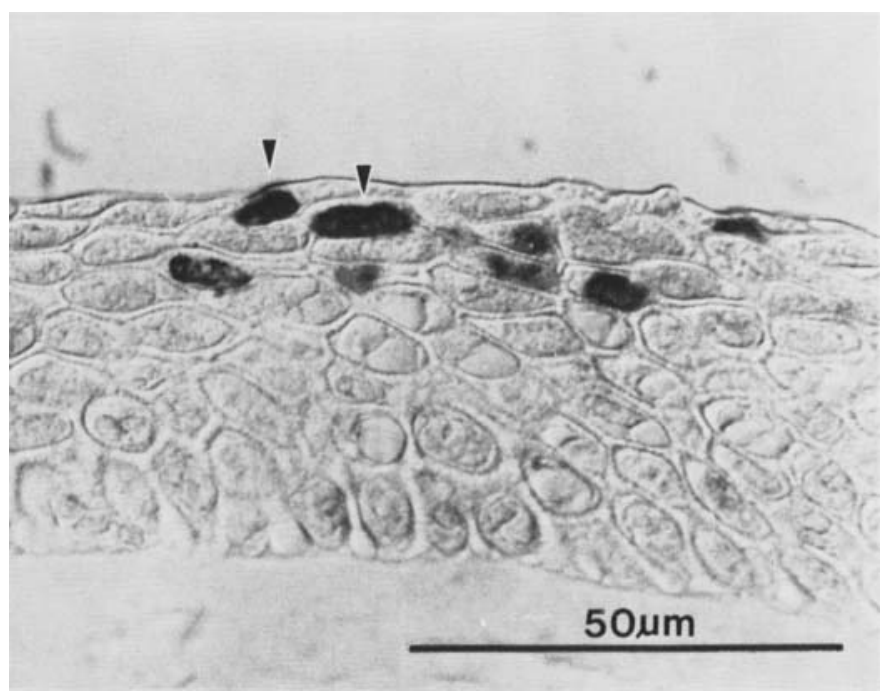

Fig. 4. BrdU labelled cornea. The labelled cells are on the outer surface.

also observed labelled cells, probably astrocytes, in the retinal portion of the optic nerve, so faulty injections can be ruled out. Therefore we conclude that 2 of the unlabelled retinae were unlabelled because they contained no proliferating cells when the BrdU was available. In the other 3 , there were neither labelled corneal cells nor labelled cells in the optic nerve root, so we excluded these retinae, and restricted our analysis to the 5 . The quantitative aspects are summarized in Table 1.

The few labelled marginal retinal cells were very much closer to the proliferative zone than in the juveniles. The labelled cell in Figure $2 b$, for example, was clearly in the inner nuclear layer, but only one cell diameter removed from the unstratified margin. This implies that very little new retina was generated at the margin over the preceding 4 weeks, by comparison with the juvenile retina in Figure $2 a$. This conclusion is also consistent with a comparison of the numbers of labelled cells. In the yearlings, the margin contained either no labelled cells or only one, rarely more, and never the large number typical of juveniles. We conclude that retinal proliferation at the margin is very much less vigorous in the yearling than in the juvenile, and never, in our sample, produced ganglion cells.

The labelled central retinal cells were similar in all respects to those in the juvenile, as indicated in Figure $3 \mathrm{c}$ and $\mathrm{d}$. They occurred slightly less frequently than in the juveniles, as Table 1 shows, but it must be remembered that the retinae of the yearlings are larger than those of the juveniles, so the number of labelled central clusters may be about the same, per retina.

(ii) Tritiated thymidine. Nine of the frogs in series I, and 8 of those in series II, survived to produce autoradiograms of the eyes. None of the series I retinae had any labelled cells. Two from series II were unlabelled. The other 6 were labelled, but more sparsely than the juveniles. Three of the labelled retinae had only isolated cells in central retina, no nests. The other 3 , those with labelled nests, were from the same 3 frogs whose other retina contained nests of BrdU labelled cells.

The fact that none of the series I retinae were labelled by thymidine may be attributed to radiation damage over the intervening 4 weeks, as proposed a few paragraphs earlier. The variable labelling in the series

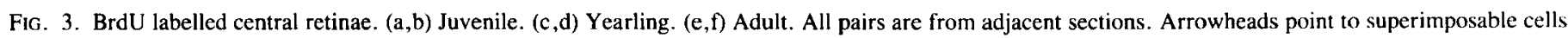
in each section. Orientation: pigment epithelium down, inner limiting membrane up. Abbreviations: as in Figure 2. 

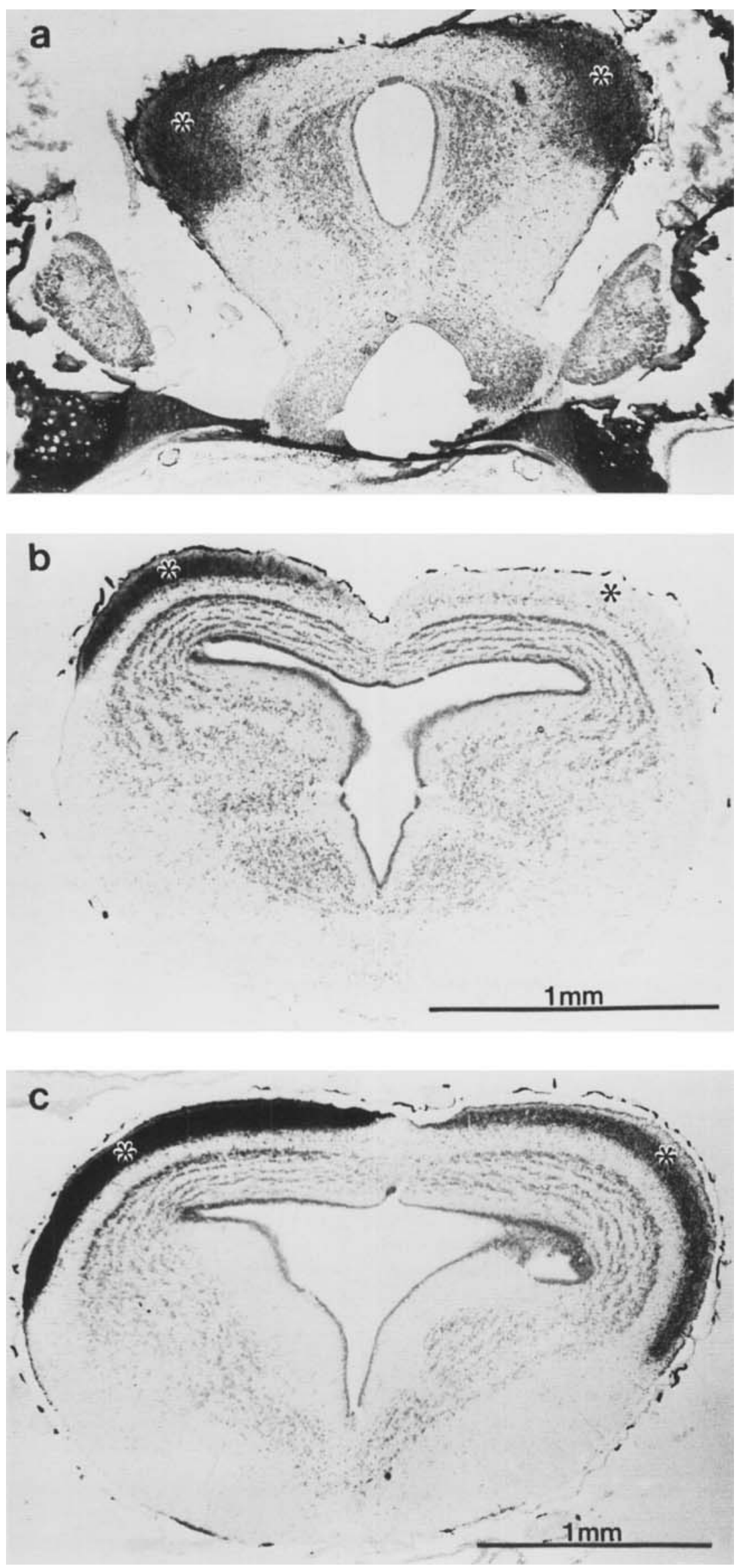
II retinae, which survived only $10-11$ days after thymidine injection, is consistent with the BrdU labelling in the contralateral eye.

We conclude-primarily from the BrdU results, weakly supported by the autoradiography - that in some of the yearlings, there was light proliferation at the retinal margin, and in other cases, none. Central retinal proliferation continued at roughly the same level as in juveniles.

Adults. (i) BrdU. All of the results were from animals that survived 6 weeks after injection. Of the original 10,2 were used as controls, and 2 more died before reaching BrdU analysis, leaving 6. Labelling at the retinal margin was very sparse, and restricted to the region adjacent to the unlaminated germinal zone, as shown in Figure $2 \mathrm{c}$. As in the yearlings, in most instances there were either no labelled cells, or only a single one, and rarely more. No labelled cells were found in the ganglion cell layer.

Central retinal nests of labelled cells resembled those of the younger animals, as Figure $3 \mathrm{e}$ and $\mathrm{f}$ illustrates. The incidence of these nests was about the same as in the yearlings.

The data from the adults are summarized in Table 1.

(ii) Tritiated thymidine. Of the 10 frogs in series I, 2 were lost in histological processing, and 7 showed no evidence of labelling in either the neural retina or cornea. One animal died during the optic nerve surgery, and because its eye had been injected with tritiated thymidine 4 days earlier, it was fixed and processed for autoradiography. Labelled cells were found in the cornea and, alone or in small groups, in the inner and outer nuclear layers, sparsely distributed throughout the central retina. No labelled cells were found in the marginal retina. The presence of labelled cells in the retina and cornea after 4 days survival, and the absence after 6 weeks, lends support to our conjecture that the labelled progeny died from the effects of radiation.

Of the 10 frogs in series II, 2 were used as controls, 1 was lost in histological processing, and 1 showed no labelled cells. In the other 6 , which had been injected 7 days before fixation, labelled cells were found in both the cornea and the neural retina. The retinal labelling was restricted to the inner and outer nuclear layers.

In summary, marginal proliferation was much reduced in the 10 year old animals, relative to the juveniles, and about the same as in the yearlings. Indeed, the retina had probably stopped adding new ganglion cells entirely, because no labelled ganglion cells were seen even after a 6 week survival. Therefore the 10 year old Xenopus appears to be a reasonably good subject with which to test the hypothesis that neurogenesis and axonal regeneration are linked.

\section{Regeneration in vivo}

We found no systematic differences in regeneration between series I and II, so we treat them as a single group. The juveniles, yearlings, and adults are described in turn.

Seventeen of the 20 juvenile animals survived to be injected in one eye with tritiated proline. Of these, 5 were lost in histological processing, leaving a total of 12 . Two were unlabelled. Ten were labelled bilaterally. Labelling in the tract was heaviest in the superficial, subpial layer, consistent with the previous description of regenerated optic axons (Gaze and Grant, 1978). Terminal labelling was seen in the thalamic, pretectal, and tectal retinorecipient zones. This aberrant bilateral projection is only seen in regenerated pathways (Gaze and Jacobson, 1963). An example at the level of the tectum is shown in Figure 5a.

Of the yearlings, 2 were used as controls, leaving 18 for regeneration. All survived to be injected with proline. Of these, 2 were unlabelled, and 16 were labelled bilaterally. In all cases the level of contralateral labelling was greater than that seen on the ipsilateral side, as Figure $5 \mathrm{~b}$, one of the most asymmetric cases, illustrates.

Of the adults, 2 were used as controls, and 3 others died, leaving 15 for regeneration. Of these, 2 were unlabelled, and 13 showed bilateral projections to visual centres. In all cases the level of labelling was greater contralaterally than ipsilaterally. Figure $5 \mathrm{c}$ shows an example.

In summary, all ages regenerated: $10 / 12$ juveniles, $16 / 18$ yearlings, and $13 / 15$ adults. In all cases, aberrant ipsilateral projections were formed that had not existed prior to optic nerve section. We conclude that the animals regenerated their optic nerve fibres irrespective of age.

\section{Regeneration in vitro}

Retinal explants from animals of all ages produced neuritic outgrowth. In goldfish retinal explants, such neurites have been shown to originate from ganglion cells (Johns et al., 1978), and we assume that the same is true for Xenopus. The patterns of axon outgrowth differed according to the age of the donor. The only previous studies of Xenopus retinal explants dealt with embryonic and larval tissue (Agranoff et al., 1976; Harris et al., 1985; Grant and Tseng, 1986), so our observations will be described with reference to them. Most comparisons are made of explants that spent 5 days in culture; at this time outgrowth was at or near its maximum in all samples.

The explants from juveniles attached to the substrate relatively firmly and produced fibres during the first 2 days of culture. Between days 2 and 3, axons extended radially from the explant, forming a halo. This is qualitatively similar to the appearance of larval explants on days $2-3$, but the number of axons in the halo appears to be lower in the juvenile. The numbers of axons and the diameter of the halo increased steadily over the 5 day period studied. Figure 6a shows an example.

The explants from yearlings produced a less dense halo than the juveniles, but the fibres tended to be longer (Fig. 6b).

The explants from adults did not adhere well to the substrate or survive beyond the 5 days, but this proved long enough to observe axonal outgrowth. The halo was sparse by comparison to that of younger donors, but the axons were found to have grown to relatively greater lengths (Fig. 6c). The number of fibres arising from the adult explants appeared to be less at all times during outgrowth and showed less increase over the 5 days than the retinae from the younger conspecifics.

In summary, all explants, irrespective of the age of the donor, sent out axons, but the pattern and robustness of the outgrowth did depend upon the age. The differences in neurite outgrowth could be the result of age-related differences in the regenerative abilities of the ganglion cells. This possibility was checked by culturing retinal explants from different regions of the same adult retinae: peripheral (youngest), intermediate, and central (oldest). In all cases, the patterns of outgrowth were similar for all three, suggesting that the differences were retinaspecific and not ganglion-cell-age-specific.

FIG. 5. Autoradiographs of transverse sections of tecta. Asterisks indicate labelled neuropil. (a) Juvenile. (b) Yearling. (c) Adult. The left eye had been injected with tritiated thymidine the day before sacrifice. Orientation: dorsal is up, right is to the left. 

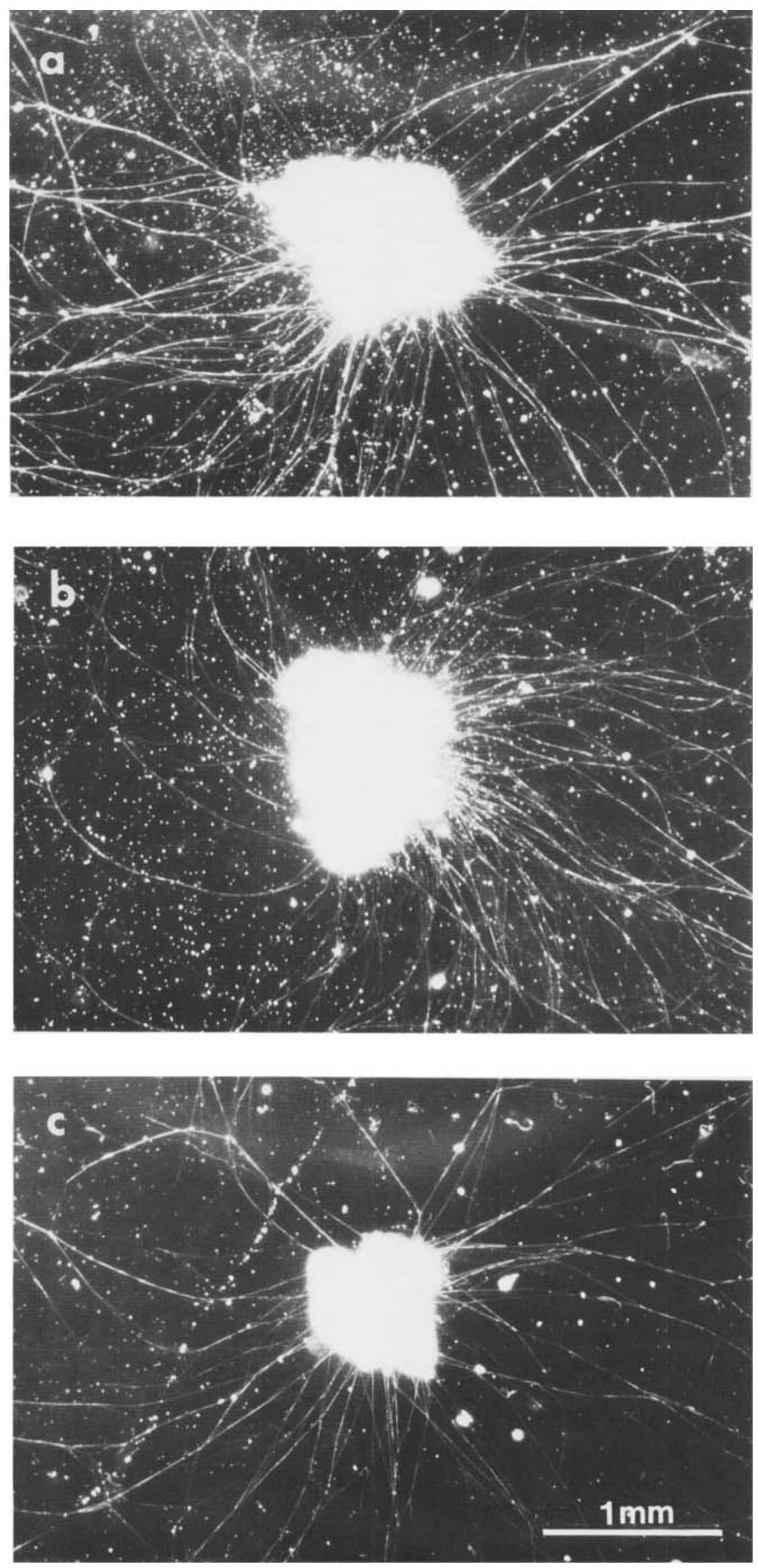
A further consideration, eliminated by this experiment, was the role of the marginal retina. In central and intermediate explants, there was no unstratified marginal zone. Even so, all of the explants regenerated axons. We conclude that the marginal retina and its secretions, if any, were not essential for regeneration.

\section{Discussion}

\section{Regeneration}

These experiments have shown unequivocally that optic axons regenerate in 10 year old Xenopus. The alternative explanation for the labelled optic pathways and targets in vivo is that the initial lesions were ineffective. This possibility was ruled out by our control experiments, and by the abnormal ipsilateral projections that appeared after weeks. The normal projections are overwhelmingly contralateral, and exclusively so to the tectum. The only way to account for the extensive ipsilateral projection is by regeneration.

In our in vitro experiments, the explanted retinae showed differences in the pattern of axonal outgrowth. The younger ones grew more profusely, forming a halo-shaped mat in contrast to the relatively stringy sets of fasciculated axons that emanated from the older ones. This difference is probably due, in part, to the smaller number of ganglion cells in the explants from the older retinae. The planimetric density (number per unit area) of ganglion cells is lower in adult eyes than in juveniles (Dunlop and Beazley, 1984; Straznicky and Hiscock, 1984; Grant and Keating, 1986), and because the explants were all of roughly the same size, the explants from older donors would have contained fewer cells. In addition, there may be intrinsic differences in the ganglion cells, dependent upon the ages of the donors. Recent work has shown that only about half of the ganglion cells in a given retina survive axotomy and subsequent nerve regeneration (Humphrey and Beazley, 1985; Beazley et al., 1986; Jenkins and Straznicky, 1986; Stelzner and Strauss, 1986). The factors that determine cell survival are unknown. It is conceivable that all cells regenerate their axons and then some fail to make a stable connection in the brain, as has been demonstrated in the development of the chick (Rager and Rager, 1976) and monkey (Rakic and Riley, 1983). Alternatively, not all functional classes may be able to regenerate axons, and those that cannot, disappear. Perhaps the ability to regenerate diminishes unevenly across the population-some cells keep it, others lose it. Finally, one other possibility we should consider is if proliferating retinal cells are providing some form of growth factor required directly or indirectly by the ganglion cells for regeneration. If in the adult retina there is generally less proliferation, then the supply of such a factor would be expected to be diminished. In vitro we would expect the low levels of cell proliferation to continue and therefore the levels of any factor would be correspondingly low compared to those of younger explants. This could account for the age-related differences in the pattern of axon outgrowth. Such differences would be relatively easy to test in vitro using co-culturing and conditioned medium.

The regenerated optic axons in the old frogs differed from the younger ones in one other respect-they did not transport HRP, as their younger conspecifics do (Taylor and Gaze, 1985).

In summary, retinal ganglion cell axons from all ages of frogs regenerated their axons, in vivo and in vitro, but there were age-specific differences.

\section{Proliferation}

First, we will discuss why our autoradiography was generally unsatisfactory. We do not think that the fixation and subsequent procedures were badly done because the sections with no labelled cells on the retinal margin had a few labelled cells elsewhere, such as the cornea, and because slides of brains labelled with tritiated proline were developed in the same batches, and they showed good autoradiographic labelling. A more likely explanation is that the dose of thymidine was too high, and killed the proliferating cells. The dose, $10 \mu \mathrm{Ci} / \mathrm{gm}$ eye weight, was chosen because intraperitoneal injections typically use $10 \mu \mathrm{Ci} / g m$ body weight. Since most of the weight of the eye is in the vitreous fluid, which is largely acellular, then the dose per gram retina weight was very high indeed. We suggest that the cells that were initially labelled by the tritiated thymidine were subsequently killed by the very radioactive nucleic acids that they synthesized. This view is supported by the cases in which retinal labelling was present after short survival times. We have included these thymidine data because the problem of radiation toxicity is rarely considered. BrdU does not apparently have such complications, and we base most of our conclusions on that label. None of the tritiated thymidine autoradiography, even taken at face value, would change any of them.

Did the adult retinae add new neurons? They certainly added new cells, both centrally and marginally, but at a very low rate in the yearlings and the adults. Moreover, neither of our probes-BrdU nor tritiated thymidine-produced labelled ganglion cells, even after a wait of 4 weeks in the yearlings, or 6 weeks in the adults.

This aspect of our results agrees with Grant and Keating (1986), who reported no labelling in the marginal retina of 10 year old Xenopus. But Grant and Keating provided a second, related line of evidence that seemed inconsistent with the absence of label. They counted cells in the ganglion cell layer in frogs of various ages up to 10 years and found that the number increased with age. The computed rate of addition decelerated steadily after metamorphosis: $10,800 /$ month from stage 64 to 3 months after metamorphisis (MAM), 900/month from 3 to 12 MAM, and $267 /$ month from 12 to 120 MAM. No time points were examined between 12 and 120 MAM.

These two observations-that mitotic probes failed to reveal new ganglion cells, and that cell counts suggested that new cells were added-are obviously in conflict as Grant and Keating (1986) acknowledged. They reconciled them by proposing that cells might be added to the ganglion cell layer by some means other than mitosis, for example, migration from another layer. They offered no evidence in support, but we note that rod precursors in teleost retinae have been shown to move between the inner and outer nuclear layers, so there seems no obvious reason to exclude migration into the ganglion cell layer.

While we cannot categorically reject this interpretation, we are more inclined to challenge the data. That is, we favour the view that one set of observations is misleading.

The mitotic probes might not adequately reveal cell proliferation. As we have noted, the dose of thymidine used by Grant and Keating (1986) was almost certainly too low to have reliably labelled all dividing cells. Our BrdU unquestionably labelled cells (see Figs $2-4$ ), but it might have been available too briefly to label a significant fraction of a sluggishly proliferative cell population. According to this argument, the dividing cells that went on to produce ganglion cells were missed

FIG. 6. Explanted retinal fragments with radiating neurites. (a) Juvenile. (b) Yearling. (c) Adult. All had been in vitro for 5 days. See Figure 1 and text for details. 
by the BrdU, and so the ganglion cells were not detected. We think that this is unlikely because the distance from the most peripheral labelled cell to the unstratified retinal margin was so small in both the yearlings and the adults that there was scarcely any room for new ganglion cells. Moreover, in the great majority of margins, no cells were labelled. Therefore we are inclined to accept the BrdU results at face value.

The number of nuclei in the ganglion cell layer of adult Xenopus has been estimated independently at least five times, but the counts are open to serious question. The estimates vary widely: 78,400 (Wilson, 1971), 68,500 (Graydon and Giorgi, 1984), 110/120,000 (Straznicky and Hiscock, 1984), 71/8200 (Dunlop and Beazley, 1984), 91,400 (Grant and Keating, 1986). The ages of the 'adults' varied: 2 years (Wilson, 1971), unspecified (Graydon and Giorgi, 1984), 'fully grown female' (Straznicky and Hiscock, 1984), 5-6 years (Dunlop and Beazley, 1984), and 10 years (Grant and Keating, 1986). In some of these studies, methodological problems lead one to doubt the accuracy of the counts. These problems include: the small number of retinae used (2), the small fraction of the retina sampled $(0.1 \%)$, and the failure to take into consideration variations in the planimetric densities of cells in the ganglion cell layer. The variety phenotype of the cells in the ganglion cell layer also raises problems with some of these counts. Wilson (1971), and Straznicky and Hiscock (1984), excluded certain cell types, on the basis of morphology, as being non-ganglion cells. The other three studies included all nuclei in the layer and therefore included non-ganglion cells. Several studies have indicated that such cells may contribute as much as $25 \%$ to the total number of cells in the ganglion cell layer of the adult (Wilson, 1971; Dunlop and Beazley, 1984). Given the uncertainty of the nature of the cells with their somata in the ganglion cell layer, and the variability in the estimates of the total number, we suggest that such cell counts provide a poor basis from which to conclude whether or not a relatively small number of new ganglion cells are added to the retina during adulthood. The mitotic probes are probably more instructive.

Therefore, we accept that the Xenopus retina is a reasonably good, but imperfect, tissue on which to evaluate the hypothesis that axonal regeneration is linked to neurogenesis. The 10 year old retina does add central retinal cells, probably neurons, but it does not seem to add new ganglion cells, and therefore the system has no need, under normal circumstances, to provide for axon elongation. Even so, the axons regenerate.

We conclude that central axonal regeneration and neurogenesis are not obligatorily linked in this case. Our conclusion is qualified by the fact that retinal cells were still dividing at a very low rate, but, until a more perfect subject is found on which to do the experiment, this qualified conclusion will have to provide the most likely view.

\section{Comparison to mammals}

Perhaps the best known case of adult central nervous system regeneration is in the olfactory system. The nasal primary sensory epithelium is continually being replaced throughout the animal's life and therefore new sensory nerve fibres are continually being added to the olfactory nerve (Monti-Graziadei and Graziadei, 1979). If the olfactory nerve is damaged, the existing fibres are destroyed, but are replaced by new axons which grow along the nerve from newly generated receptor cells (Barber, 1981). Neurogenesis is therefore crucial to this type of replacement-regeneration, but is very different from the reconstitution of severed axons usually associated with other examples of regeneration.
Other examples (see the review by Björklund and Stenevi, 1979) apparently show conventional regeneration. Do the nuclei of origin of these axons continue to proliferate in the adult? The question has not been asked experimentally, but perhaps it should be.

Recent intracerebral transplantation experiments have revealed two points: (i) grafts of embryonic and neonatal material survive most readily; (ii) neurons from such grafts are capable of extending axons for considerable distances in otherwise unaltered adult brains (see Gash and Sladek, 1988). These observations suggest that an interplay of complex factors exists governing regeneration in the adult mammalian central nervous system, which may be specific for certain classes of neurons and may only be effective during critical periods of development. They also render ideas suggesting that the adult central nervous system provides an inhospitable environment for the regeneration over-simplistic. Our question would be: if the successful regeneration of a particular class of neurons is restricted to a specific 'window' during development is this related to the normal period of neurogenesis of that system?

The definition of the 'normal period of neurogenesis' is far from clear. Although it is generally accepted that in amniotes neurogenesis is an embryonic and immediately postnatal phenomenon, in certain systems neurogenesis may persist throughout life (Altman, 1970; Kaplan and Hinds, 1977; Alvarez-Buylla and Nottebohm, 1988). There have been several studies which have suggested that a correlation may exist between relatively extended periods of neurogenesis and regenerative capacity (Kalil and Reh, 1979; Bregman and Goldberger, 1982; Grafe, 1983). For example, in the olfactory tract of the hamster, axons show an ability to regenerate in early postnatal life, a period which may relate to the diminution of neurogenesis in the olfactory bulb, which peaks at embryonic day 14/15, a day before birth (Grafe, 1983).

In adulthood axons in the olfactory tract can be induced to regenerate over extensive distances if supplied with a peripheral nerve environment (Freidman and Aguayo, 1985). Indeed, Aguayo and co-workers have demonstrated the ability of selected mammalian central nervous system neurons to regenerate if allowed to enter tissue from the peripheral nervous system (Aguayo, 1985). Among the particular classes of neurons which possess this ability are the retinal ganglion cells (So and Aguayo, 1983; Villegas-Perez et al., 1988). Also in vitro, when given specific environmental conditions, adult retinal ganglion cell axons can regenerate (Ford-Holevinski et al., 1986; Bahr et al., 1988; Wigley and Berry, 1988). These observations argue that regeneration is possible in the absence of neurogenesis. However, as we have suggested, during neurogenesis some unknown factors may be produced which maintain the environment of the axon pathway at a state which will support axon growth and allow regeneration to occur in situ. Where grafted peripheral nerve tissue, or other substances conducive to axon growth, are placed near severed adult axons they apparently provide the environmental conditions required for axon elongation. This imposition of factors may substitute for any necessary factors normally only synthesized during the period of neurogenesis and axon growth. For example, it has recently been shown that the expression of the growth associated protein GAP 43 is highest during the phase of axon outgrowth, and that the subsequent decline in expression correlates with the progressive loss of regenerative ability (So et al., 1981; Moya et al., 1988). In adulthood, where GAP 43 synthesis is greatly reduced in many parts of the central nervous system (Jacobson et al., 1986), axotomy does not induce enhanced synthesis (Kalil and Skene, 1986). If extracts from a neonatal rabbit optic nerve are applied to the severed 
optic nerve of an adult, regeneration is found to occur (Hadani et al., 1984), and this may be associated with a re-expression of laminin in the optic pathway (Lavie et al., 1987). These results argue that for adult mammalian central nervous system axon regeneration to occur, either the factors synthesized by neurons during the initial period of axon outgrowth must be maintained, or that factors required for axon elongation must be reintroduced. It remains to be shown whether in those cases where regeneration of adult axons occurs in situ their nuclei of origin show continued cell proliferation and synthesis of such factors.

\section{Acknowledgements}

This work was carried out with the financial support of the Medical Research Council, the Royal Society, the Wellcome Trust to J.S.H.T. and NIH grant EY00168 to SSE. We thank Professor R. M. Gaze for his encouragement, Professor R. W. Guillery for his comments on the manuscript, Ms Maida Davidson, Ms Davina Hocking, and Mr Maurice Sanders for technical help, Ms Celeste Malinoski and Mr Terry Richards for the illustrations, and Ms Debbie Hall for typing.

\section{Abbreviations}

BrdU bromodeoxyuridine

DAB diaminobenzidine

HRP horseradish peroxidase

PBS phosphate-buffered saline

\section{References}

Agranoff, B. W., Field, P., and Gaze, R. M. (1976) Neurite outgrowth from explanted Xenopus retina: an effect of prior optic nerve section. Brain Res. 113: $225-234$.

Aguayo, A. J. (1985) In: Coleman, C.W. (ed.) Synaptic Plasticity pp. 457-484. The Guildford Press, New York.

Altman, J. (1970) In: Himwich, W. A. (ed.) Developmental Neurobiology pp. 197-237. Springfield: Thomas.

Alvarez-Buylla, A. and Nottebohm, F. (1988) Migration of young neurons in adult avian brain. Nature (Lond.) 335: 353-354.

Attardi, D. G. and Sperry, R. W. (1963) Preferential selection of central pathways by regenerating optic fibers. Exp. Neurol. 7: 46-64.

Bahr, M., Vaneslow, J., and Thanos, S. (1988) In vitro regeneration of adult rat ganglion cell axons from retinal explants. Exp. Brain Res. 73: 393-401.

Barber, P. C. (1981) Axonal growth by newly-formed vomeronasal neurosensory cells in the normal adult mouse. Brain Res. 216: 229-237.

Beach, D. H. and Jacobson, M. (1979) Patterns of cell proliferation in the retina of the clawed frog during development. J. Comp. Neurol. 198: 603-611.

Beazley, L. D., Darby, J. E., and Perry, V. H. (1986) Cell death in the retinal ganglion cell layer during optic nerve regeneration for the frog Rana pipiens. Vision Res. 26: 543-556.

Björklund, A. and Stenevi, U. (1979) Regeneration of monoaminergic and cholinergic neurons in the mammalian central nervous system. Physiol. Revs 59: $62-100$.

Bregman, B. S. and Goldberger, M. E. (1982) Anatomical plasticity and sparing function after spinal cord damage in neonatal cats. Science 217: 553-555.

Bunt, S. M. and Fill-Moebs, P. (1984) Selection of pathways by regenerating spinal cord fiber tracts. Dev. Brain Res. 16: 307-311.

Dunlop, S. A. and Beazley, L. D. (1984) A morphometric study of the retinal ganglion cell layer and optic nerve from metamorphosis in Xenopus laevis. Vision Res. 24: 417-427.

Ford-Holevinski, T. S., Hopkins, J. M., McCoy, J. P. and Agranoff, B. W. (1986) Laminin supports neurite outgrowth from explants of axotomised adult rat retinal neurons. Dev. Brain Res. 28: 121-126.

Freidman, B. and Aguayo, A. (1985) Injured neurons in the olfactory bulb of the adult rat grow axons along peripheral nerve grafts. J. Neurosci. 6: $1616-1625$.

Gash, D. M. and Sladek, J. R. (eds) (1988) Transplantation into the mammalian central nervous system. Prog. in Brain Res. 78:
Gaze, R. M. (1959) Regeneration of the optic nerve in Xenopus laevis. Q. J. Exp. Physiol. 44: 290-308.

Gaze, R. M. and Grant, P. (1978) The diencephalic course of regenerating retinotectal fibres in Xenopus. J. Embryol. Exp. Morph. 44: 201-216.

Gaze, R.M. and Jacobson, M. (1963) A study of the retinotectal projection during regeneration of the optic nerve in the frog. Proc. R. Soc. Ser B, (London) B175: 420-448.

Goldberg, S. and Frank, B. (1980) Will central nervous system, in the adult mammal regenerate after bypassing a lesion? A study in the mouse and chick visual systems. Exp. Neurol. 70: 675-689.

Grafe, M. R. (1983) Developmental factors affecting regeneration in the central nervous system: early but not late formed mitral cells reinnervate olfactory cortex after neonatal tract section. J. Neurosci. 3: 617-630.

Grant, P. and Tseng, Y. (1986) Embryonic and regenerating Xenopus retinal fibers are intriniscally different. Dev. Biol. 114: 475-491.

Grant, S. and Keating, M. J. (1986) Ocular migration and the metamorphic and postmetamorphic maturation of the retinotectal system, in Xenopus laevis: an autoradiographic and morphometric study. J. Embryol. Exp. Morph. 92: $43-69$.

Gratzner, H. G. (1982) Monoclonal antibody to 5-bromo- and 5-iododeoxyuridine: a new reagent for detection of DNA replication. Science 218: $474-475$.

Graydon, M. L. and Giorgi, P. (1984) Topography of the retinal ganglion cell layer of Xenopus. J. Anat. 139: 145-157.

Hadani, M., Harel, A., Solomon, A., Belkin, M., Lavie, V., and Schwartz, M. (1984) Substances originating from the optic nerve of neonatal rabbit induce regeneration-associated response in the injured optic nerve of adult rabbit. Proc. Natl. Acad. Sci. USA 81: 7965-7969.

Harris, W. A., Holt, C. E., Smith, T. A., and Gallenson, N. (1985) Growth cones of developing retinal cells in vivo, on culture surfaces, and in collagen matrices. J. Neurosci. Res. 13: 101-122.

Holder. N. and Clarke, J. W. D. (1988) Is there a correlation between continous neurogenesis and directed axon regeneration in the vertebrate nervous system? Trends in Neurosci. 11: 94-99.

Hollyfield, J. G. (1971) Differential growth of the neural retina in Xenopus laevis larvae. Dev. Biol. 24: 264-286.

Hopkins, J. M., Ford-Holevinski, T. S., McCoy, J. P., and Agranoff, B. W. (1985) Laminin and optic nerve regeneration in the goldfish. J. Neurosci. 5: 3030-3038.

Hoskins, S. G. and Grobstein, P. (1985) Development of the ipsilateral projection in the frog Xenopus laevis. I. Retinal distribution of ipsilaterally projecting cells in normal and experimentally manipulated frogs. J. Neurosci. 5: 911-919.

Humphrey, M. F. and Beazley, L. D. (1985) Retinal ganglion cell death during optic nerve regeneration in the frog Hyla moorei J. Comp. Neurol. 236: $382-402$.

Jacobson, M. (1976) Histogenesis of retina in the clawed frog with implications for patterns of development of retinotectal connections. Brain Res. 103: $541-545$.

Jacobson, R. D., Virag, I., and Skene, J. H. P. (1986) A protein associated with axon growth, GAP-43, is widely distributed and developmentally regulated in rat CNS. J. Neurosci; 6: $1843-1855$.

Jenkins, S. and Straznicky, C. (1986) Naturally occurring and induced cell death: a retinal whole mount autoradiographic study in Xenopus. Anat. Embryol. 174: $59-66$.

Johns, P. R. (1982) Formation of photoreceptors in larval and adult goldfish. J. Neurosci. 2: $178-198$.

Johns, P. R. and Fernald, R. D. (1981) Genesis of rods in teleost fish retina. Nature (Lond.) 293: 141-142.

Johns, P. R., Heacock, A. M., and Agranoff, B. W. (1978) Neurites in explant cultures of adult goldfish retina derive from ganglion cells. Brain Res. 142: $531-537$.

Kaplan, M. S. and Hinds, J. W. (1977) Neurogenesis in the adult rat: electron microscopic analysis of light radioautographs. Science 197: 1092-1094.

Kalil, K. and Reh, T. A. (1979) Regrowth of severed axons in the neonatal central nervous system: establishment of normal connections. Science 205: $1158-1161$.

Kalil, K. and Skene, H. J. P. (1986) Elevated synthesis of an axonally transported protein correlates with axon outgrowth in normal and injured pyramidal tracts. J. Neurosci. 6: $2563-2570$.

Kollros, J. J. (1988) Towards an understanding of tectal development in frogs. In: Pollack, E. D. and Bibb, H. D. (eds) Developmental Neurobiology of 
the Frog pp. 207-229. Alan R. Liss Inc., New York.

Kollros, J. J. and Thiesse, M. I. (1988) Control of tectal cell number during larval development in Rana pipiens. J. Comp. Neurol. 278: 430-445.

Lavie, V., Harel, A., Doron, A., Solomon, A., Lobel, D., Belkin, M. Ben-Basat, S., Sharma, S., and Schwartz, M. (1987) Morphological response of injured adult rabbit optic nerve to implants containing media conditioned by growing optic nerves. Brain Res. 419: 166-172.

Lyon, M. J. and Stelzner, D. J. (1987) Tests of the regenerative capacity of tectal efferent axons in the frog, Rana pipiens. J. Comp. Neurol. 255: $511-525$.

Matthey, R. (1927) Recupération de la vue après résection des nerfs optiques chez le Triton. C. R. Soc. Biol. 93: 904-906.

McCart, R. and Straznicky, C. (1988) Lack of axon regeneration of isthmic neurons in juvenile Xenopus. Neurosci. Letts 92: 143-148.

Monti-Graziadei, G. A. and Graziadei, P. P. C. (1979) Neurogenesis and neuron regeneration in the olfactory system of mammals. II. Degeneration and reconstitution of the olfactory sensory neurons after axotomy. J. Neurocytol. 8: $197-213$.

Moya, K. L., Benowitz, L. I., Jhaveri, S., and Schneider, G. E. (1988) Changes in rapidly transported proteins in developing hamster retinofugal axons. J. Neurosci. 8: $4445-4454$

Rager, G. and Rager, U. (1976) Generation and degeneration of retinal ganglion cells in the chicken. Exp. Brain Res. 25: 551-553.

Rakic, P. and Riley, K. P. (1983) Over production and elimination of retinal axons in the foetal rhesus monkey. Science 219: 1441-1444.

Reh, T. A. and Constantine-Paton, M. (1983) Qualitative and quantitative measures of plasticity during the normal development of the Rana pipiens retinotectal projection. Dev. Brain Res. 10: 187-200.

Richardson, P. M., Issa, U. M. K., and Shemie, S. (1982) Regeneration and retrograde degeneration of axons in the rat optic nerve. J. Neurocytol. 11: $949-966$

Skene, J. H. P. and Willard, M. (1981) Changes in axonally transported proteins during regeneration in toad retinal ganglion cells. J. Cell Biol. 89: 86-95

So, K. F. and Aguayo, A. J. (1985) Lengthy regrowth of cut axons from ganglion cells after peripheral nerve transplantation into the retina of adult rats. Brain Res. 328: 349-354.

So, K. F., Schneider, , G. E., and Ayers, S. (1981) Lesions of the brachium of the superior colliculus in neonate hamsters: correlations of anatomy with behaviour. Exp. Neurol. 72: 379-400.

Stelzner, D. J. and Strauss, J. A. (1986) A quantitative analysis of frog optic nerve regeneration: is retrograde ganglion cell death or collateral axonal loss related to selective reinnervation? J. Comp. Neurol. 245: 83-106.

Straznicky, C. and Gaze, R. M. (1971) The growth of the retina in Xenopus laevis: an autoradiographic study. J. Embryol. Exp. Morph. 26: 67-79.

Straznicky, C. and Hiscock, J. (1984) Post metamorphic retinal growth in Xenopus. Anat. Embryol. 169: 103-109.

Taylor, J. S. H. and Gaze, R. M. (1985) The effects of fibre environment on the paths taken by regenerating optic nerve fibres in Xenopus. J. Embryol. Exp. Morph. 89: 383-401.

Villegas-Pérez, M. P., Vidal-Sanz, M., Bray, G. M., and Aguayo, A. J. (1988) Influences of peripheral nerve grafts on the survival and regrowth of axotomised retinal ganglion cells in adult rats. J. Neurosci. 8: 265-280.

Wigley, C. B. and Berry, M. (1988) Regeneration of adult rat retinal ganglion cell processes in monolayer culture: comparisons between cultures of adult and neonatal neurons. Dev. Brain Res. 42: 85-98.

Wilson, M. A. (1971) Optic nerve fibre counts and retinal ganglion cell counts during development of Xenopus laevis (Daudin). Q. J. Exp. Physiol. 56: $83-91$ 